\title{
Ecosystem photosynthesis regulates soil respiration on a diurnal scale with a short-term time lag in a coastal wetland
}

\author{
Guangxuan Han ${ }^{\mathrm{a}}$, Yiqi Luo ${ }^{\mathrm{b}}$, Dejun $\mathrm{Li}^{\mathrm{b}}$, Jianyang Xia ${ }^{\mathrm{b}}$, Qinghui Xing ${ }^{\mathrm{a}}$, Junbao $\mathrm{Yu}^{\mathrm{a}, *}$ \\ ${ }^{a}$ Key Laboratory of Coastal Environmental Processes and Ecological Remediation, Yantai Institute of Coastal Zone Research, \\ Chinese Academy of Sciences, Yantai, Shandong 264003, China \\ ${ }^{\mathrm{b}}$ Department of Microbiology and Plant Biology, University of Oklahoma, Norman, OK 73019, USA
}

\section{A R T I C L E I N F O}

\section{Article history:}

Received 27 July 2013

Received in revised form

17 September 2013

Accepted 25 September 2013

Available online 4 October 2013

\section{Keywords:}

Soil respiration

Ecosystem photosynthesis

Eddy covariance

Sunny and cloudy days

Coastal wetland

Yellow River Delta

\begin{abstract}
A B S T R A C $T$
Although increasing evidence has provided that soil respiration is strongly related to recent canopy photosynthesis, doubts remain as to the extent to which primary productivity controls soil respiratory and the speed of the link between soil respiration and photosynthesis. Based on the automated measurements of soil respiration and eddy covariance measurements of ecosystem photosynthesis (i.e. gross primary production, GPP) in a coastal wetland, we assessed the speed of link between ecosystem photosynthesis and soil respiration on the diurnal scale, and quantified the control of the ecosystem primary production on diurnal soil respiration. On the diurnal scale, the time of daily peak soil respiration lagged GPP but preceded soil temperature on both sunny and cloudy days. Daytime soil respiration was significantly linearly correlated with GPP with a lag of $1.5 \mathrm{~h}$ on sunny days and $1 \mathrm{~h}$ on cloudy days, respectively. By taking advantage of the natural shift of sunny and cloudy days without disturbance to the plant-soil system, our results also indicated that the changes in soil temperature and GPP together explained $53 \%$ of the changes in daytime soil respiration rates between sunny days and adjacent cloudy days. Under the same soil temperature, changes in soil respiration rates were strongly correlated with changes in GPP between sunny days and adjacent cloudy days. We therefore conclude that recent canopy photosynthesis regulates soil respiration on a diurnal scale with a short-term time lag. Thus, it is necessary to take into account the influence of photosynthesis on soil respiration in order to accurately simulate the magnitude and variation of soil respiration, especially at short and medium temporal scales.

(c) 2013 Elsevier Ltd. All rights reserved.
\end{abstract}

\section{Introduction}

It is well documented that soil respiration may lag canopy photosynthesis by times that vary from hours to weeks in different ecosystems including forests (Högberg et al., 2001; Tang et al., 2005; Baldocchi et al., 2006; Moyano et al., 2008; Wingate et al., 2010), grasslands (Bahn et al., 2008, 2009; Yan et al., 2011; Vargas et al., 2011a) and croplands (Kuzyakov and Cheng, 2001, 2004; Han et al., 2007). The highly variable time lags between photosynthesis and soil respiration might be controlled by the species, transport distance (plant height and phloem path-length), root depth, plant physiology and growth stage, and environmental conditions (Davidson and Holbrook, 2009; Kuzyakov and Gavrichkova, 2010; Mencuccini and Hölttä, 2010; Wingate et al., 2010). For example, leaf metabolism including the switch between a mobile sugar and a

\footnotetext{
* Corresponding author. Tel.: +86 535 2109113; fax: +86 5352109000 .

E-mail addresses: gxhan@yic.ac.cn (G. Han), jbyu@yic.ac.cn (J. Yu).
}

transient immobile carbon pool determined the interaction between assimilation and soil respiration on a diurnal timescale (Barthel et al., 2011). The lag time was shorter for grasses and shrubs than for trees, because tree height slightly affected the lag with increasing delay of 0.1 day $\mathrm{m}^{-1}$ (Davidson and Holbrook, 2009; Kuzyakov and Gavrichkova, 2010). In addition, gas diffusion through soil imposed a lag between the time of $\mathrm{CO}_{2}$ production at depth and release from the soil surface (Stoy et al., 2007; Phillips et al., 2011), which also influenced the time lags. Consequently, the time lag between the fixation of a carbon molecule during photosynthesis and its respiration belowground contains real information about plant physiology and carbon use as well as the degree to which plant and soil are coupled (Kayler et al., 2010).

The time lags between photosynthesis and soil respiration provide evidence of close links between recent photosynthate supply and soil respiration at different timescales. In contrast to the indirect connection between temperature and soil respiration, the tight linkage between photosynthesis and soil respiration processes is direct (Kuzyakov and Gavrichkova, 2010). Soil respiration is 
derived from heterotrophic and autotrophic sources. In principle, autotrophic soil respiration is a direct consequence of root respiration, so it is coupled to rates of photosynthesis (Baldocchi et al., 2006). Meanwhile, the flux of recent photosynthate supports substantial microbial activity in the rhizosphere, which can in turn influence the relative fraction of heterotrophic respiration (Cardon et al., 2002; Tang et al., 2005). Consequently, half or more of the soil respiration is driven directly by recent photosynthesis, which challenges the assumption that most of the soil respiration is derived from the decomposition of soil organic matter (Kuzyakov and Cheng, 2001; Bhupinderpal-Singh et al., 2003; Högberg and Read, 2006). Therefore, any short-term changes of assimilation rates caused by day/night light cycles may potentially control the diurnal dynamics of soil respiration (Kuzyakov and Cheng, 2004).

Although important, this fact has been overlooked in most soil respiration studies because temperature variations are highly correlated with solar radiation, which mask the direct effect of photosynthesis on substrate availability in soil, especially on diurnal scale (Tang et al., 2005; Gaumont-Guay et al., 2008; Kuzyakov and Gavrichkova, 2010). For example, the diurnal soil respiration is controlled by the photosynthesis cycle together with temperature changes (Kuzyakov and Cheng, 2001; Davidson and Holbrook, 2009; Phillips et al., 2011), so it is difficult to distinguish the degree to which canopy processes and temperature influence root activity, which can easily lead to erroneous conclusions on temperature relations (Moyano et al., 2008). Moreover, although soil temperature of soil respiration is important for modellingpurposes, it might be inadequate to account for the diurnal variation of soil respiration (Tang et al., 2005; Liu et al., 2006). Therefore, further studies are needed to better quantify the effect of canopy photosynthesis on soil respiration especially at short and medium temporal scales (Tang et al., 2005; Moyano et al., 2008; Kuzyakov and Gavrichkova, 2010).

Furthermore, previous studies have provided evidence that soil respiration is strongly related to recent canopy photosynthesis on different time scales ranging from several hours to several days using phloem girdling (Ekblad and Högberg, 2001; Högberg et al., 2001), shading and clipping (Wan and Luo, 2003; Yan et al., 2011), root exclusion by trenching (Kuzyakov and Larionova, 2005; Gaumont-Guay et al., 2008), and isotopic labelling studies of photosynthate (Kuzyakov and Cheng, 2001, 2004; Ekblad et al., 2005; Högberg et al., 2008; Barthel et al., 2011; Wingate et al., 2010). However, doubts remain as to the extent to which primary productivity controls soil respiratory and the speed of the link between soil respiration and photosynthesis (Gaumont-Guay et al., 2008; Kayler et al., 2010). For instance, the immediate link of soil respiration to photosynthesis is still uncertain on the diurnal scale (Bahn et al., 2009). Therefore, current major challenges remain ahead of us for developing process-based models of soil respiration at short and medium temporal scales, including the lags and transport of carbon from photosynthesis to soil respiration (Vargas et al., 2011b).

The development of automated soil respiration measurements and eddy covariance (EC) techniques with high temporal resolution enables us to examine the role of photosynthesis supply in modulating soil respiration on the diurnal timescale. We hypothesized that ecosystem photosynthesis can regulate soil respiration at hourly temporal resolution. To test these hypotheses, we selected 12 paired days during the growing season in a coastal wetland under the following two criteria: (1) the two days are adjacent, one is a sunny day, and another is a cloudy day; (2) no rain occurs during the two adjacent days. We hypothesized that (1) live biomass and leaf area index (LAI) have no large shifts within the two adjacent days; (2) soil moisture has no significant difference between the two adjacent days because no rain occurs; (3) soil organic carbon (SOC) and plant litterfall have not changed substantially within the short term. Therefore, by limiting variability from these factors, we expected during such conditions the radiation condition exerted a major control on soil respiration by altering temperature and plant photosynthetic activity. The purpose of this study was to (1) assess the speed of link between ecosystem photosynthesis and soil respiration on the diurnal scale; (2) quantify the control of the ecosystem primary production on diurnal soil respiration in a coastal wetland.

\section{Materials and methods}

\subsection{Site description}

The experiment was conducted during the growing season (from mid April to early November) of 2012 at Yellow River Delta Ecological Research Station of Coastal Wetland $\left(37^{\circ} 45^{\prime} 50^{\prime \prime} \mathrm{N}, 118^{\circ}\right.$ $\left.59^{\prime} 24^{\prime \prime} \mathrm{E}\right)$, Chinese Academy of Sciences. The original vegetation of coastal wetlands in the Yellow River Delta is composed of halophytic plant communities predominated by herb and shrub species, such as Phragmites australis, Suaeda salsa, and Imperata cylindrical (Han et al., 2013). The terrain of the station is quite flat, with relatively homogeneous vegetation dominated by reed (Phragmites australis), which usually bud during the end of March and the first 10 days of April, and head in the middle 10 days of October (Xie et al., 2011; Han et al., 2013). The climate in the Yellow River Delta is a warm-temperate and continental monsoon climate with distinctive seasons. The annual average temperature is $12.9^{\circ} \mathrm{C}$, and the average annual precipitation is $550-640 \mathrm{~mm}$, with nearly $70 \%$ of the precipitation falling between May and September. During the rainy season, surface ponding is often observed in Phragmites australis community, following heavy rainfall events. Generally, the soil type of coastal wetlands in the Yellow River Delta gradually varies from fluvo-aquic to saline soil, and the soil texture is mainly sandy clay loam (Nie et al., 2009).

\subsection{Soil respiration measurements}

Soil respiration was recorded continuously using a LI-8100 automated soil $\mathrm{CO}_{2}$ flux measurement system and LI-8150 multiplexer with four 8100-104 long-term chambers (Li-Cor Inc, Lincoln, NE, USA). Four soil collars with a height of $11.4 \mathrm{~cm}$ and diameter of $21.3 \mathrm{~cm}$ were inserted into the soil one week before the first measurement. Living weeds inside the collars were carefully clipped from the soil surface. The soil collars were left in place throughout the entire study period (from mid April to early November). Each collar was measured at least once every $2 \mathrm{~h}$ during the growing season. The chamber was closed for $120 \mathrm{~s}$ and the linear increase of $\mathrm{CO}_{2}$ concentration in the chamber was used to estimate soil respiration. In 2012, the greatest daily rainfall of $71.8 \mathrm{~mm}$ occurred on 6 August because of Typhoon Damrey. Consequently, soil respiration could not be measured from the August to mid-October because surface water flooded the soil collars.

\subsection{EC measurements}

Ecosystem $\mathrm{CO}_{2}$ fluxes were measured using a paired EC system mounted $3.0 \mathrm{~m}$ above the soil surface. The EC system included a three-axis sonic anemometer (CSAT-3, Campbell Scientific Inc., USA) and open path infrared gas analyzer (IRGA, LI-7500, Li-COR Inc., USA). The flux data were recorded at $10 \mathrm{~Hz}$ by a datalogger (CR1000, Campbell Scientific Inc., USA) at 30 min intervals. Raw EC data collected from a Campbell Scientific datalogger were processed with EdiRe (v.1.4.3.1186) from the University of Edinburg (Scotland) to determine net ecosystem $\mathrm{CO}_{2}$ exchange (NEE) with an 

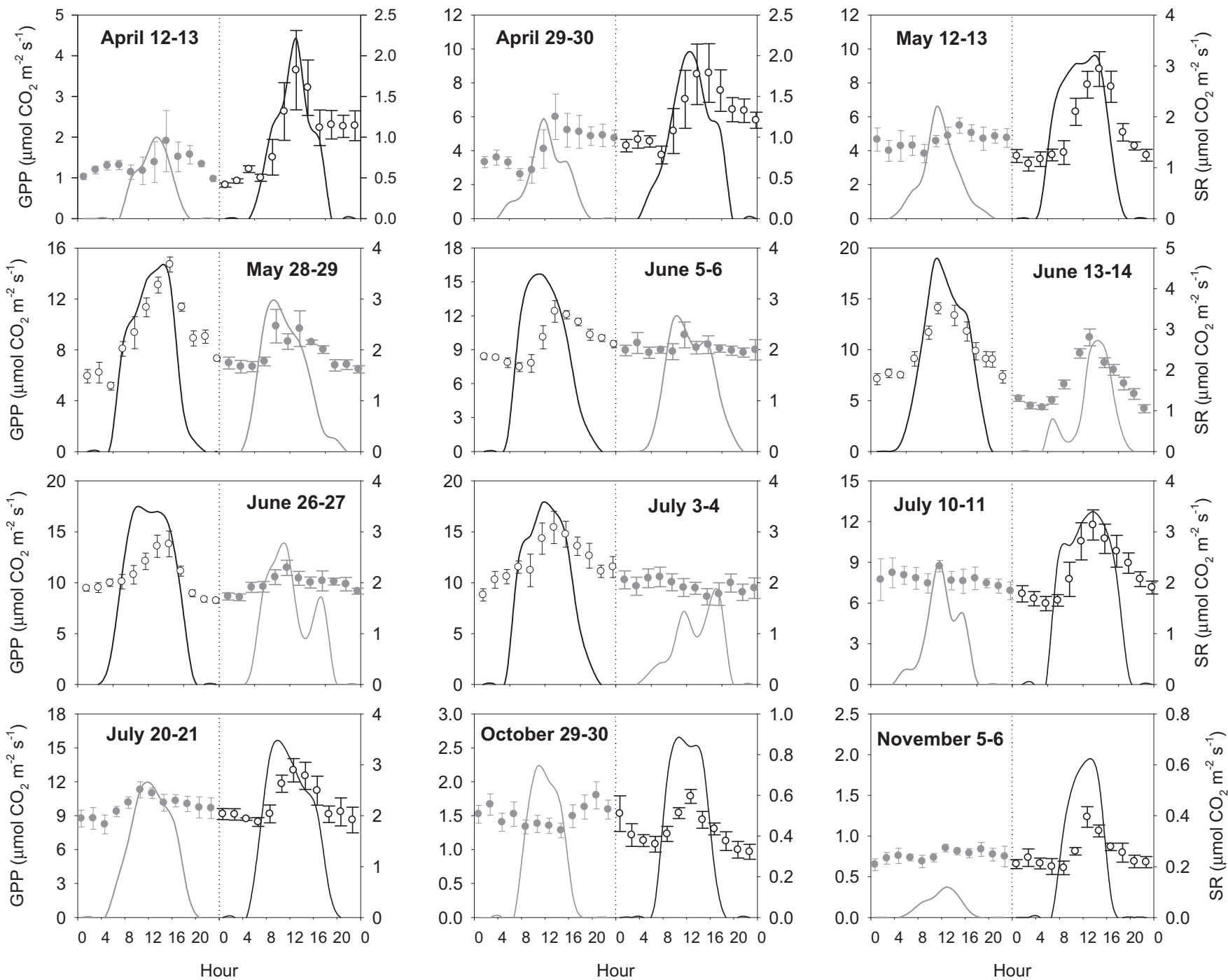

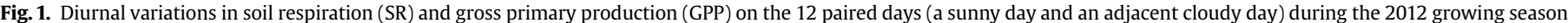

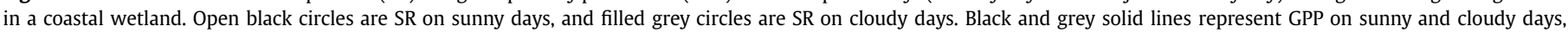
respectively. Data of SR represent means \pm standard error $(n=4)$. Data of SR are measured once every 2 h and data of GPP are presented as 30 -min average.

averaging period (30 min). Data processing followed standard methods and included despiking, coordinate rotation, time lag corrections, and air density corrections. We used the following procedure to fill missing and bad data. Small gaps (less than $2 \mathrm{~h}$ ) were filled by linear interpolation. Large gaps (more than $2 \mathrm{~h}$ ) were filled based on empirical models separately for daytime and nighttime data. More details about flux data processing, quality control and gap filling presented elsewhere (Han et al., 2013).

Nighttime $N E E$ data $\left(R_{\text {eco, night }}\right)$ were filled with the exponential

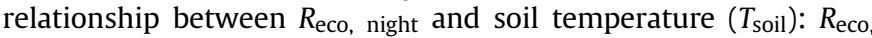
night $=\mathrm{a} \exp \left(\mathrm{b} T_{\mathrm{soil}}\right)$. Based on the assumption that daytime ecosystem respiration ( $\left.R_{\text {eco, day }}\right)$ follows the same temperature response, $R_{\text {eco, day }}$ was determined using the exponential relationships developed for nighttime periods (Han et al., 2013). Using the values of $R_{\text {eco, day, }} G P P$ was calculated as the balance between $R_{\text {eco, }}$ day and daytime $N E E: G P P=R_{\text {eco, day }}-N E E$.

\subsection{Meteorological measurements}

Meteorological parameters were measured simultaneously with an array of sensors, including photosynthetically active radiation
(PAR) (LI-190SB, Li-Cor Inc., USA), air temperature (HMP45C, Vaisala, Helsinki, Finland), wind speed and direction (034B, Campbell Scientific Inc., USA), atmospheric pressure (CS106, Campbell Scientific Inc., USA), and precipitation (TE525 tipping bucket gauge, Texas Electronics, Texas, USA). Soil temperature was measured at five depths ( $5 \mathrm{~cm}, 10 \mathrm{~cm}, 20 \mathrm{~cm}, 30 \mathrm{~cm}$ and $50 \mathrm{~cm}$ ) with thermistors (109SS, Campbell Scientific Inc., USA). Soil water content (SWC) was measured by time domain reflectometry probes (EnviroSMART SDI-12, Sentek Pty Ltd., USA) at seven depths $(10 \mathrm{~cm}, 20 \mathrm{~cm}, 30 \mathrm{~cm}$, $40 \mathrm{~cm}, 60 \mathrm{~cm}, 80 \mathrm{~cm}$ and $100 \mathrm{~cm}$ ). All meteorological data were measured every $15 \mathrm{~s}$ and then averaged half-hourly.

\subsection{Statistical analysis}

In order to analyse the effect of photosynthesis on soil respiration, we selected 12 paired days (a sunny day and an adjacent cloudy day) during the growing season under two criteria as mentioned in the Introduction. A lag regression analysis was used to assess the correlation between mean daytime soil respiration and GPP during the daytime (PAR $>0$ ) under both sunny and cloudy conditions. A two-tailed two-sample $t$-test was used to test 
the significant differences in meteorological factors (PAR, temperature, atmospheric pressure, and SWC), the mean rates of soil respiration, and GPP between the sunny days and the adjacent cloudy days. In all tests, a significance level of $P=0.05$ was used.

To determine the respective influence of GPP and soil temperature on daytime soil respiration, linear and exponential regression analyses were used. Linear regression was used to evaluate the effect of GPP on daytime soil respiration on sunny and cloudy days, respectively. In a previous study, correlation analysis revealed that soil respiration was more significantly related to soil temperature and soil water content of the top layer than at the deeper depths (from $20 \mathrm{~cm}$ to $80 \mathrm{~cm}$ ) (Han et al., 2012). Thus, we only used the data of soil temperature at $5 \mathrm{~cm}$ depth and SWC at $10 \mathrm{~cm}$ depth to investigate the influence of temperature or moisture on soil respiration. On the basis of the observed data, we established an exponential function to describe the relationship between soil respiration and soil temperature: $S R=a \mathrm{e}^{b T}$, where $S R$ is soil respiration ( $\mu \mathrm{mol} \mathrm{CO} \mathrm{Cm}^{-2} \mathrm{~s}^{-1}$ ), $T$ is soil temperature $\left({ }^{\circ} \mathrm{C}\right)$, $\mathrm{a}$ and $\mathrm{b}$ are model parameters. In addition, linear and stepwise multiple regression analysis were applied to examine effects of the changes in GPP and soil temperature between sunny and cloudy days on the changes in daytime soil respiration. The significance level was set at $P<0.05$.

Soil temperature variations are highly correlated with solar radiation (Kuzyakov and Gavrichkova, 2010), and they will jointly affects GPP. In order to avoid soil temperature masking the direct effect of GPP on soil respiration, we compared the daytime soil respiration of sunny and cloudy days under the same soil temperature. At first, the exponential equation between soil respiration and soil temperature on cloudy days was established. Then, soil respiration on cloudy days was adjusted using the exponential equation and the same soil temperature of the corresponding sunny days. Lastly, a linear regression was used to evaluate the effect of the changes in GPP between sunny days and adjacent cloudy days on the changes in daytime soil respiration under the same soil respiration. All statistical analyses were performed using SPSS 11.5 (SPSS for Windows, Chicago, IL, USA).

\section{Results}

\subsection{Diurnal variation of soil respiration rates}

The diurnal courses of GPP, soil temperature and soil respiration from the 12 paired days from April to November in 2012 are presented in Fig. 1. In order to compare the diurnal variation of soil respiration under different radiation condition, data of GPP, soil respiration and soil temperature were averaged from 12 sunny days and 12 adjacent cloudy days, respectively (Fig. 2a and b). On a sunny day, the diurnal variation of half-hourly GPP showed a symmetrical patter (a bell shape) with the peak almost exactly at noon, and the diurnal patterns of soil respiration varied correspondingly with GPP (Figs. 1 and 2a). While on an adjacent cloudy day, there was no regular diurnal variation in GPP, and soil

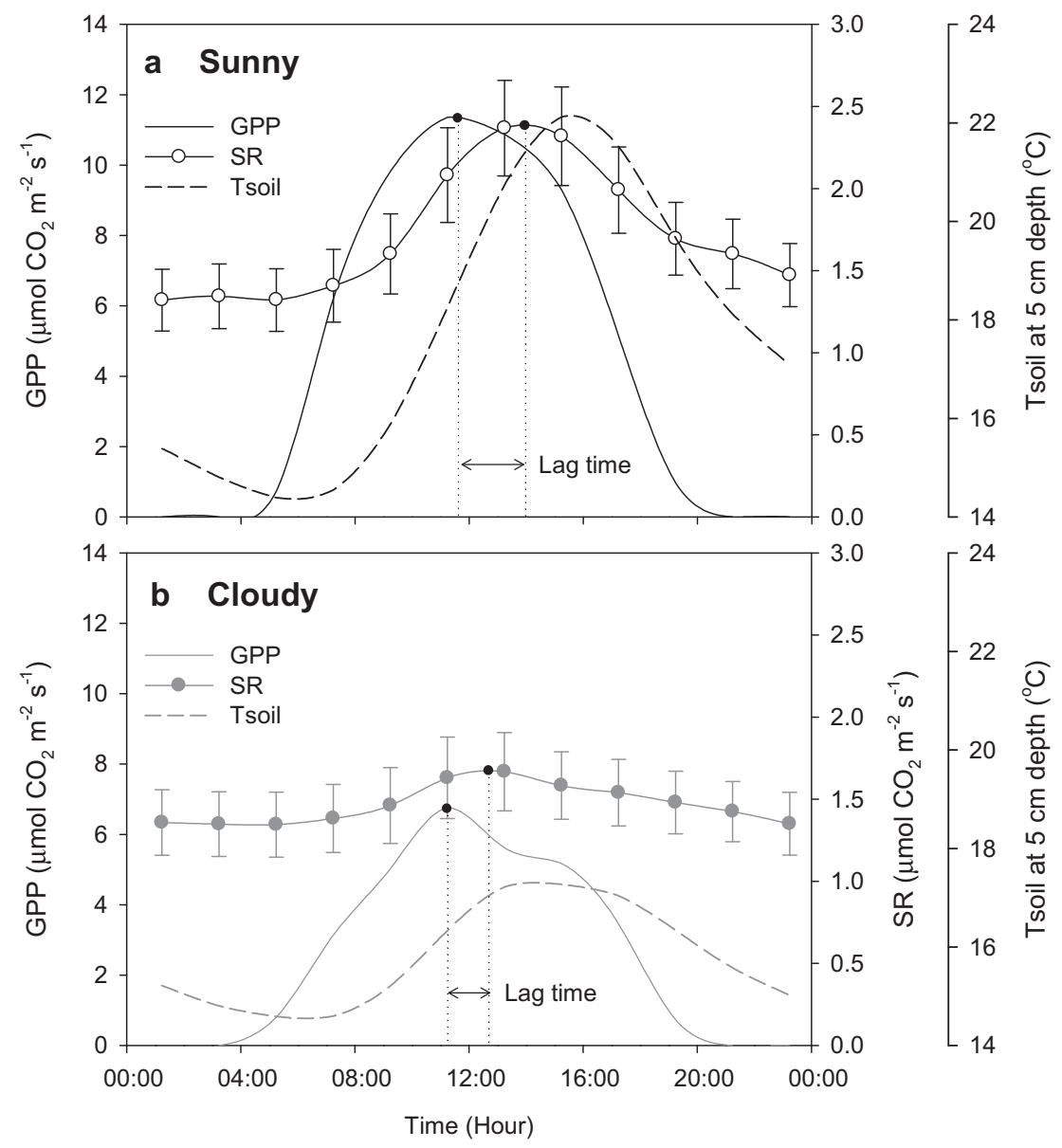

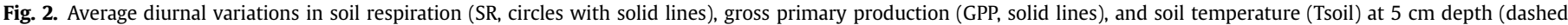

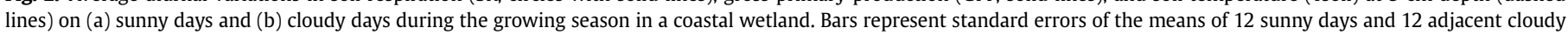
days, respectively. Lag times between the peak of SR and the peak of GPP are indicated by dotted lines. 
Table 1

Lag times between the peak of soil respiration (SR) and the peak of gross primary production (GPP), and proportion of SR to GPP (SR/GPP) on sunny days and adjacent cloudy days, respectively.

\begin{tabular}{|c|c|c|c|c|c|}
\hline \multicolumn{3}{|l|}{ Sunny days } & \multicolumn{3}{|l|}{ Cloudy days } \\
\hline Date & $\begin{array}{l}\text { Lag } \\
\text { time (h) }\end{array}$ & $\begin{array}{l}\text { SR/GPP } \\
(\%)\end{array}$ & Date & $\begin{array}{l}\text { Lag } \\
\text { time }(\mathrm{h})\end{array}$ & $\begin{array}{l}\text { SR/GPP } \\
(\%)\end{array}$ \\
\hline April 13 & 0 & 47.8 & April 12 & 2 & 54.8 \\
\hline April 30 & 2 & 22.9 & April 29 & 2 & 31.3 \\
\hline May 13 & 2 & 33.1 & May 12 & 4 & 60.2 \\
\hline May 28 & 2 & 31.0 & May 29 & 0 & 31.4 \\
\hline June 5 & 2 & 24.0 & June 6 & 2 & 30.3 \\
\hline June 13 & 0 & 27.1 & June 14 & 0 & 40.9 \\
\hline June 26 & 4 & 20.1 & June 27 & 0 & 28.5 \\
\hline July 3 & 2 & 23.6 & July 4 & 1 & 44.0 \\
\hline July 11 & 0 & 26.1 & July 10 & 0 & 54.2 \\
\hline July 21 & 2 & 23.7 & July 20 & 0 & 30.2 \\
\hline October 30 & 2 & 23.8 & October 29 & 1 & 26.9 \\
\hline November 6 & 0 & 21.1 & November 5 & 0 & 40.5 \\
\hline Average & 1.5 & 27.0 & Average & 1 & 39.4 \\
\hline
\end{tabular}

respiration rates were lower and fluctuated within a relatively narrow range as compared to that of sunny day (Figs. 1 and $2 \mathrm{~b}$ ).

On a diurnal scale, mean daytime soil respiration lagged GPP but preceded soil temperature (Fig. 2a and b). In the early morning hours (4:00-7:00), although soil temperature decreased, soil respiration increased gradually coinciding with increasing GPP levels. Meanwhile, in the afternoon hours (14:00-20:00), soil respiration decreased slightly following the decreasing trend of GPP (Fig. 2a and b). The peak in soil respiration lagged behind the peak in GPP by about $1.5 \mathrm{~h}$ (varying from $0 \mathrm{~h}$ to $4 \mathrm{~h}$ ) on sunny days and about $1 \mathrm{~h}$ (also varying from $0 \mathrm{~h}$ to $4 \mathrm{~h}$ ) on cloudy days (Table 1 , Fig. 2a and b). At daytime, the proportion of soil respiration to GPP was about $27.0 \%$ on sunny days and about $39.4 \%$ on cloudy days (Table 1).

Plots of mean daytime soil respiration against GPP produced hysteresis loops on both radiation conditions (Fig. 3a, c). There was no significantly linear relationship between mean daytime soil respiration and GPP on both sunny and cloudy days (Fig. 3a and d). However, a lag regression analysis showed that soil respiration was significantly linearly correlated with GPP with a lag of $1.5 \mathrm{~h}$ on sunny days $\left(R^{2}=0.87, P<0.001\right.$; Fig. $\left.3 \mathrm{~b}\right)$ and $1 \mathrm{~h}$ on cloudy days $\left(R^{2}=0.89, P<0.001\right.$; Fig. $\left.3 \mathrm{~d}\right)$, respectively.

\subsection{Effect of GPP on daytime soil respiration}

During the daytime, PAR on sunny days $(452.2 \pm$ $\left.62.0 \mu \mathrm{mol} \mathrm{m} \mathrm{m}^{-2} \mathrm{~s}^{-1}\right)$ showed significantly higher $(P<0.001)$ than those values on adjacent cloudy days $\left(149.1 \pm 25.4 \mu \mathrm{mol} \mathrm{m}^{-2} \mathrm{~s}^{-1}\right)$ (Fig. 4a), when data were averaged over the 12 paired sampling dates. Since the cloudiness reduced the incoming radiation during daytime, the amplitude of soil temperature at $5 \mathrm{~cm}$ depth was significantly lower by $1.8^{\circ} \mathrm{C}(P<0.01)$ on cloudy days as compared to that of sunny days (Fig. 4b). No significant difference in SWC at $10 \mathrm{~cm}$ depth and atmospheric pressure were detected $(P>0.05)$ between sunny daytime and cloudy daytime (Fig. 4c, d).

Cloudy conditions also led to lower average values of both GPP and daytime soil respiration as compared with sunny days (Fig. 4e and $\mathrm{f})$. There was a significant reduction $(P<0.001)$ in GPP $(43.6 \%)$ on cloudy daytime $\left(4.35 \pm 0.41 \mu \mathrm{mol} \mathrm{CO}_{2} \mathrm{~m}^{-2} \mathrm{~s}^{-1}\right)$ compared to the adjacent sunny daytime $\left(7.71 \pm 0.61 \mu \mathrm{mol} \mathrm{CO} \mathrm{m}^{-2} \mathrm{~s}^{-1}\right)$ (Fig. 4e). Similarly, there was a statistically significant decrease $(P<0.001)$ in soil respiration $(19.0 \%)$ on cloudy daytime $(1.58 \pm 0.08 \mu \mathrm{mol}$ $\mathrm{CO}_{2} \mathrm{~m}^{-2} \mathrm{~s}^{-1}$ ) as compared to that of adjacent sunny daytime $\left(1.95 \pm 0.10 \mu \mathrm{mol} \mathrm{CO} \mathrm{CO}^{-2} \mathrm{~s}^{-1}\right.$ ) (Fig. 4e). Overall, PAR, soil temperature, GPP and soil respiration under cloudy daytime were significant lower than those values under sunny daytime, which implies that cloudiness may limit soil respiration rates by reducing soil temperature and GPP.

Daytime soil respiration was positive linear with GPP on both sunny and cloudy days $\left(r^{2}=0.49, P<0.001\right.$ and $r^{2}=0.39, P<0.001$, respectively; Fig. 5a). Meanwhile, there were significant exponential relationships between daytime soil respiration and soil temperature at $5 \mathrm{~cm}$ depth on sunny and cloudy days $\left(r^{2}=0.81\right.$, $P<0.001$ and $r^{2}=0.87, P<0.001$, respectively; Fig. 5b). Thus, changes in daytime soil respiration between sunny and cloudy days increased linearly with changes in GPP $\left(r^{2}=0.18, P<0.0001\right.$; Fig. 5c) and changes in soil temperature $\left(r^{2}=0.43, P<0.0001\right.$; Fig. 5d), respectively. Stepwise multiple regression analyses suggested that changes in soil temperature (partial $r^{2}=0.43$, $P<0.001$ ) and GPP (partial $r^{2}=0.10, P<0.001$ ) together explained $53 \%$ of the changes in daytime soil respiration rates between sunny and cloudy days (Table 2), indicating the diurnal soil respiration is controlled by the ecosystem photosynthesis together with temperature changes. In addition, in order to analyse the direct effect of changes in GPP on changes in soil respiration, we compared the daytime soil respiration of sunny and cloudy days under the same soil temperature. Under the same soil temperature, changes in GPP were adequate to predict the changes in daytime soil respiration between sunny and cloudy days $\left(r^{2}=0.18, P<0.001\right.$; Fig. 6$)$.

\section{Discussion}

\subsection{Time lag between GPP and soil respiration on a diurnal scale}

The daily hysteresis pattern results from a lag of several hours between soil respiration and recent photosynthesis, which has also been found in a number of studies (e.g. Tang et al., 2005; RiverosIregui et al., 2007; Davidson and Holbrook, 2009; Phillips et al., 2011; Vargas et al., 2011a). In general, diurnal soil respiration lagged photosynthetic activity on hourly scales (e.g. Baldocchi et al., 2006; Liu et al., 2006; Bahn et al., 2008; Yan et al., 2011). The time lags of $0-4 \mathrm{~h}$ in our results are consistent with previous findings. For example, a free air $\mathrm{CO}_{2}$ enrichment experiment (FACE) in a mixed deciduous forest showed that the diurnal cycle of soil respiration was correlated with PAR with a $1 \mathrm{~h}$ lag (Liu et al., 2006), and a pulselabelling experiment also showed that under sunny conditions photoassimilates in a mountain grassland were transported and respired belowground within less than $2 \mathrm{~h}$ (Bahn et al., 2009). More recently, soil respiration showed significant responses to plant photosynthetic activity with a time lag of about $0-3 \mathrm{~h}$ in a steppe ecosystem (Yan et al., 2011). These short-term time lags between photosynthesis and soil respiration suggest potentially that soil respiration is a close link between recent photosynthate and soil respiration processes (Kuzyakov and Gavrichkova, 2010). Meanwhile, the short-term time lags also indicate that the recent canopy carbon supply into soil might be respired quickly by soil respiration than previously assumed. Clearly, the fate of recent assimilates is key in describing the degree to which plant assimilatory and soil respiratory processes are coupled (Kayler et al., 2010).

Several studies have discussed the potential mechanisms on how GPP influences soil respiration on a diurnal scale. Firstly, there might be a fast transport of recent photosynthesis and substrate supply from the canopy to the soil (Högberg et al., 2008; Bahn et al., 2009; Vargas et al., 2011a). High transport rates of assimilates from leaves into roots and their subsequent loss in the processes of root respiration have been demonstrated by previous laboratory experiments (e.g. Gregory and Atwell, 1991; Cheng et al., 1993; Kuzyakov et al., 2001). Secondly, autotrophic respiration may dominate the soil respiration signal on a diurnal scale during the 

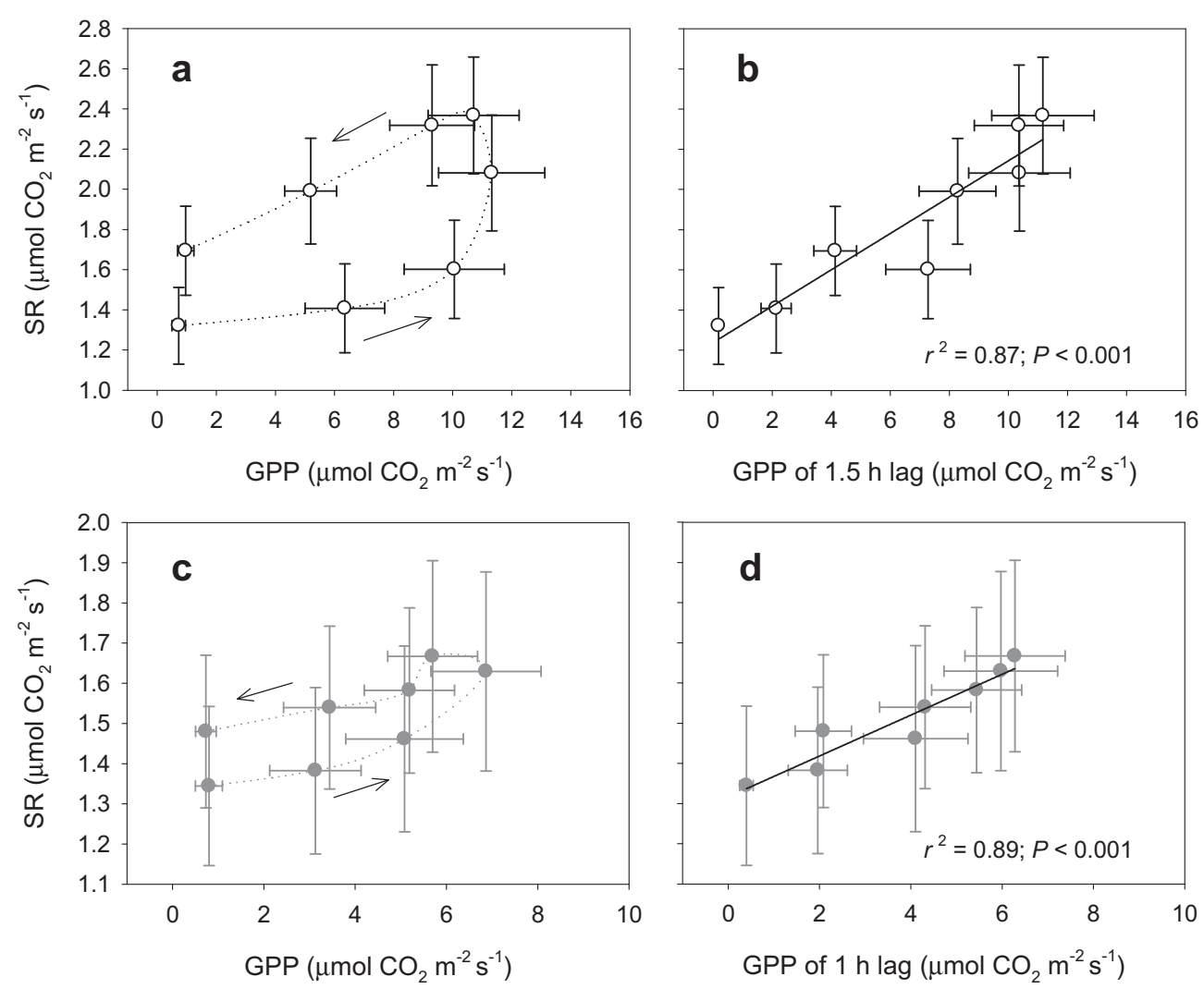

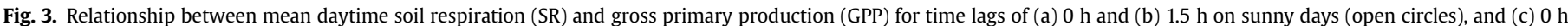

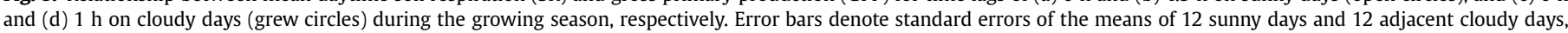

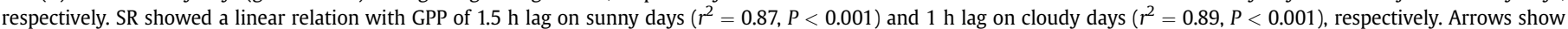
direction of the hysteresis loop of diurnal changes.

growing season (Vargas et al., 2011a). Thirdly, temperature might be inadequate to account for the diurnal variation of soil respiration (Tang et al., 2005; Liu et al., 2006; Yan et al., 2011) because radiation not only affect temperature but also drive canopy photosynthesis. Therefore, incorporating the time lag in the models will significantly increase their precision, especially on the time scale of hours and days (Kuzyakov and Gavrichkova, 2010).

\subsection{GPP regulates diurnal soil respiration on an ecosystem scale}

Cloudiness decreased daytime soil respiration by $19.0 \%$ $(P<0.001$; Fig. 4f) as compared to that of adjacent sunny daytime, which might result from two compatible mechanisms. On the one hand, cloudiness decreased soil temperature $(P<0.001$; Fig. 4 b), thereby limiting the rate of soil respiration. It is clear that soil respiration generally responds positively to increased soil temperature when water is not limited at different temporal scales in a number of ecosystems (e.g. Davidson and Janssens, 2006; Han et al., 2007; Bond-Lamberty and Thomson, 2010). On the other hand, lower PAR and soil temperature on cloudy days $(P<0.001$; Fig. 4 a, b) reduced canopy photosynthesis $(P<0.001$; Fig. 4e), consequently decreasing translocation of recent photosynthates to the rhizosphere, which might affect both maintenance respiration and growth of roots, mycorrhizae, and rhizosphere microorganisms (Davidson and Holbrook, 2009). As a result, substrate limitation in the rhizosphere may have reduced the rate of soil respiration. In addition, the enhancement of convective flows in PAR can have a considerable influence on root radial oxygen loss in Phragmites australis (Armstrong and Armstrong, 1988, 1990), which plays an important role in the physicochemical environment of the rhizosphere, particularly for wetland plants growing in oxygen deficient waterlogged soils (Blossfeld et al., 2011). As a consequence, the difference in root radial oxygen loss between sunny and cloudy days can lead to the changes in rhizosphere biogeochemistry (e.g. Blossfeld et al., 2011), resulting in changes in rhizosphere respiration.

Under the same soil temperature, changes in daytime soil respiration rates were regulated ultimately by the difference in GPP between sunny and cloudy days (Fig. 6), suggesting recent carbon assimilation is a key driver of soil respiration (Kuzyakov and Gavrichkova, 2010). Recent ecosystem photosynthates to the rhizosphere may control belowground respiration processes in several ways. Firstly, autotrophic soil respiration was constrained by the allocation of products to belowground, which was tightly coupled with photosynthesis of the canopy (Högberg and Read, 2006). Consequently, root respiration was very sensitive to changes in photosynthesis, and it decreased significantly without photosynthesis (Högberg et al., 2001; Kuzyakov and Cheng, 2004; Ekblad et al., 2005). Secondly, heterotrophic soil respiration originated from decomposition of litter and soil organic matter, of which the availability also depended on primary productivity (Yan et al., 2011). In situ ${ }^{13} \mathrm{CO}_{2}$ pulse labelling experiment demonstrated that recently assimilated carbon was allocated to the pool of microbial biomass within 1 day in a cutover peatland (Trinder et al., 2008). The ability of microorganisms to decompose additional soil organic matter decreased when easily-decomposable substrates decreased due to the absence of photosynthesis (Kuzyakov and Cheng, 2001). Thirdly, the respiration of mycelium has also been found to be dependent on newly produced photosynthates (Söderström and Read, 1987). More of the belowground carbon flux was made 

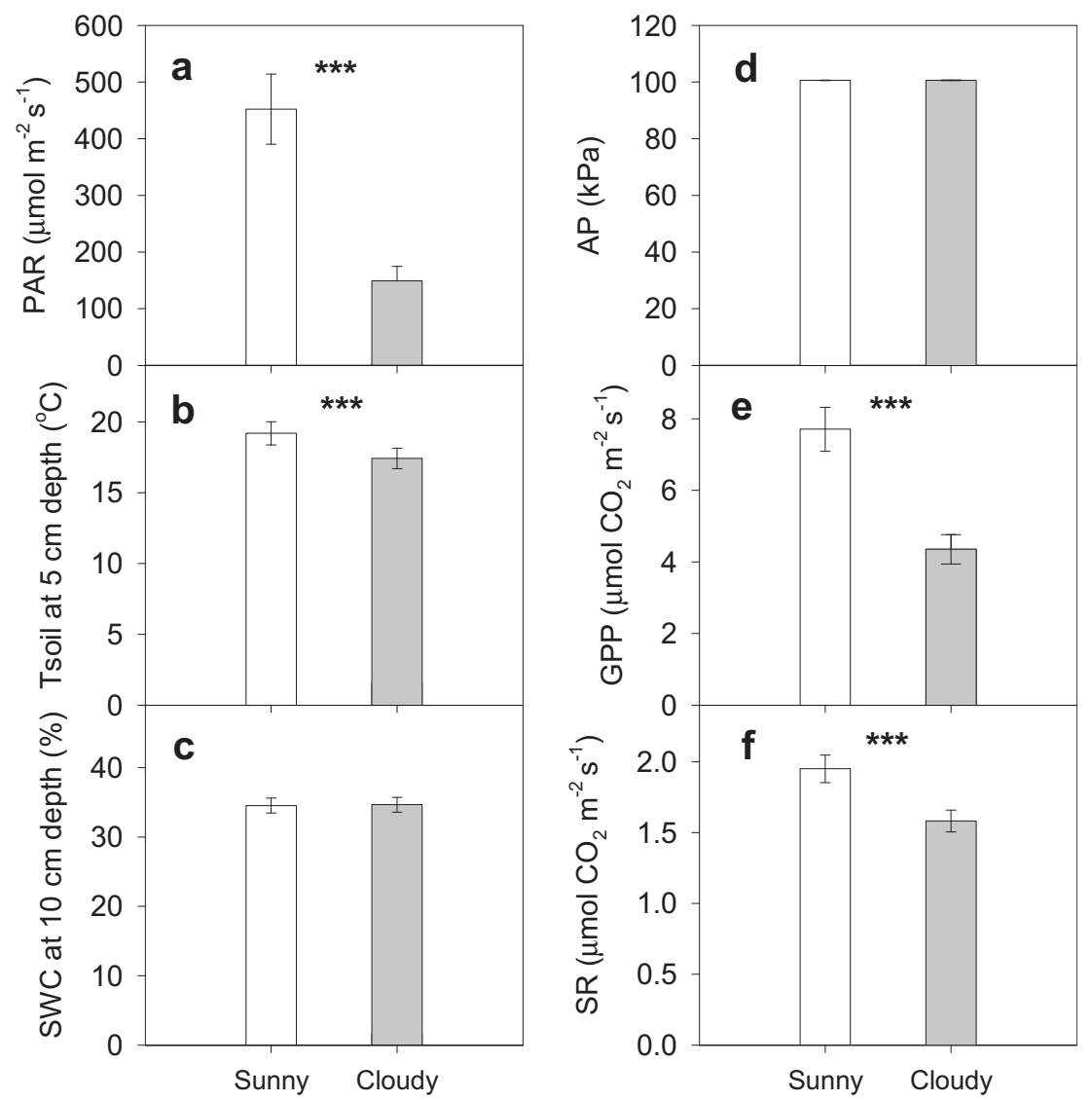

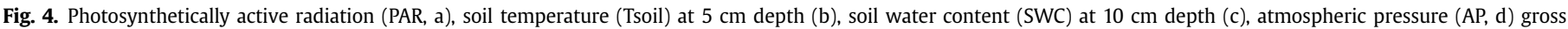

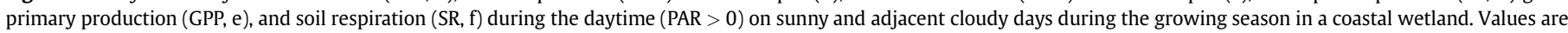

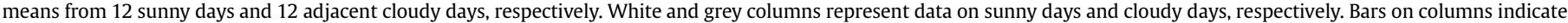
standard error. Significance level (two-tailed two-sample $t$-test, ${ }^{* * *} P<0.001$ ) are shown in the figure.

available to mycorrhizal fungi and other soil biota closely associated with roots (Högberg and Read, 2006). Therefore, changes in photosynthesis could affect soil respiration via alterations in belowground substrate availability (Sampson et al., 2007). For example, the daily GPP was linearly correlated with daily soil respiration during the growing season (Irvine et al., 2005), and the newly produced photoassimilates could even account for $65 \%-70 \%$ of total soil respiration (Ekblad and Högberg, 2001; Högberg et al., 2001; Søe et al., 2004). Hence, the models of soil respiration should consider photosynthesis or radiation (a direct proxy of photosynthesis) as one of the main drivers in the theoretical explanation or modelling of soil respiration (Tang et al., 2005; Sampson et al., 2007; Moyano et al., 2008; Kuzyakov and Gavrichkova, 2010; Mencuccini and Hölttä, 2010), since the ultimate source of carbohydrates for root and soil microbial respiration is primarily plant photosynthate (Davidson and Holbrook, 2009). For example, incorporation of PAR responses into models of diurnal soil respiration improved predictions for fluxes measured from a mixed conifer and oak forest in California (Vargas and Allen, 2008).

\subsection{Features, limitations and perspectives of the study}

By taking advantage of the natural shift of sunny and cloudy days, this study determined that ecosystem photosynthesis regulated soil respiration on a diurnal scale. This approach can limit the variability of other controlling factors, such as biomass and LAI, soil moisture, SOC and plant litterfall, based on undisturbed field measurements without manipulation. Furthermore, the combination of the automated measurements of soil respiration and EC measurements of ecosystem photosynthesis brings us the data resources with high time resolution, which provides the possibility to test the hypothesis that ecosystem photosynthesis regulates soil respiration on a diurnal timescale.

Using different indirect methods (e.g. trenching, girdling of trees, shading and clipping of aboveground biomass), previous studies have evaluated the effect of radiation or photosynthesis on soil respiration and the speed of their links (Högberg et al., 2001; Wan and Luo, 2003; Gaumont-Guay et al., 2008; Yan et al., 2011). These indirect approaches and their disturbance inherently involved possible alterations of factors such as heterotrophic respiration, radiation, temperature, moisture, and plant physiological responses to cutting (Kuzyakov and Cheng, 2001; Wan and Luo, 2003; Gaumont-Guay et al., 2008), which might lead to various errors and limit their applicability (Kuzyakov and Gavrichkova, 2010). Moreover, using these indirect approaches, it is difficult to quantify individually the effect of abiotic and biotic factors on diurnal variation of soil respiration, because these variables tend to covary on a diurnal scale (Liu et al., 2006). Although isotope studies can offer the advantage that measurements involve no soil disturbance (Kuzyakov and Gavrichkova, 2010; Mencuccini and Hölttä, 2010), they are not well suited to provide evidence to show that sudden changes in canopy photosynthesis rapidly affect substrate availability for respiration (Mencuccini and Hölttä, 2010). For example, ${ }^{13} \mathrm{CO}_{2}$ could not obtain a greater resolution unless long labelling periods or very high ${ }^{13} \mathrm{CO}_{2}$ concentrations were used, which would be associated with very high financial costs (Carbone 

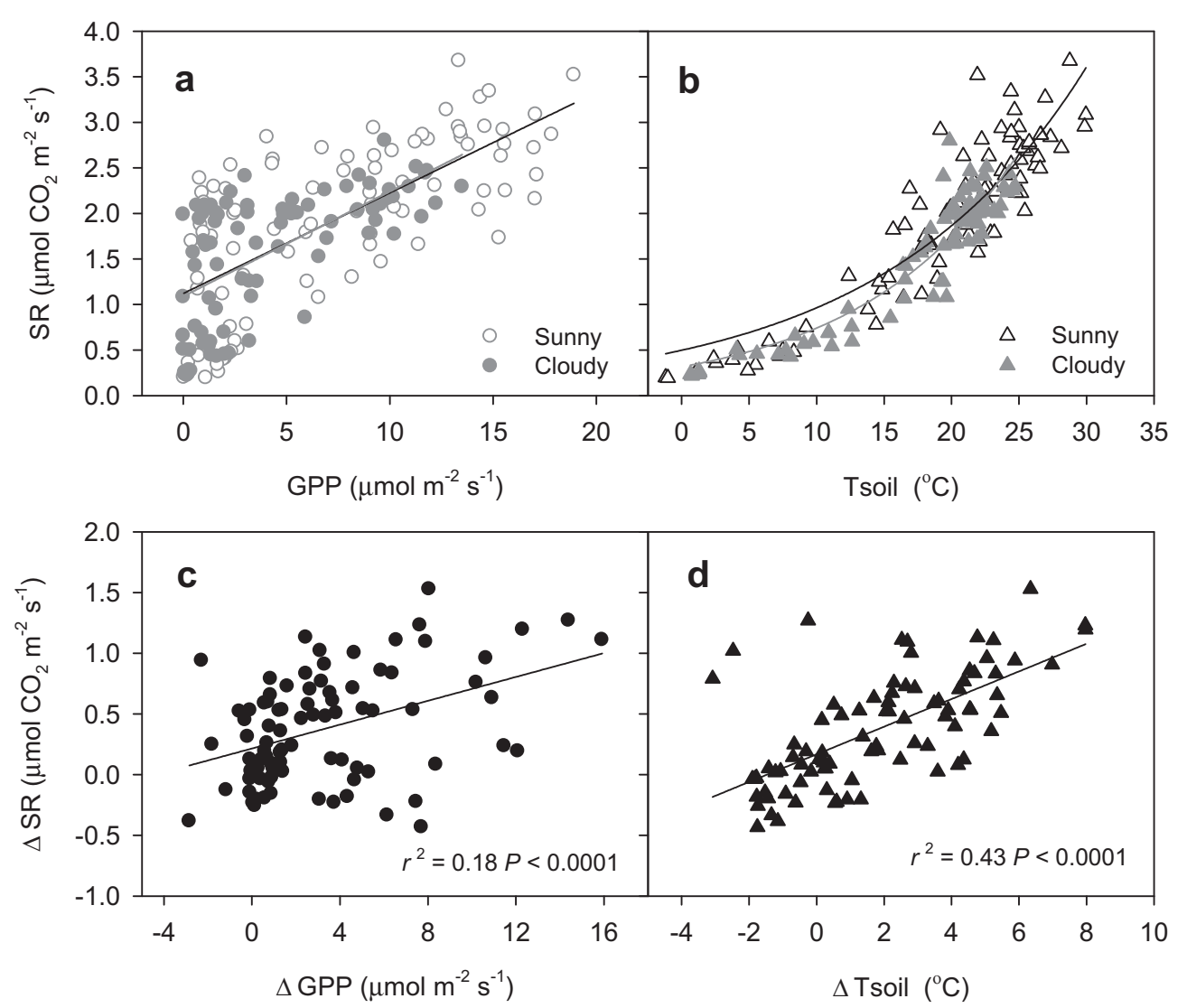

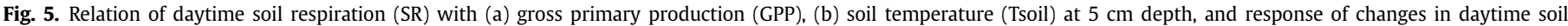

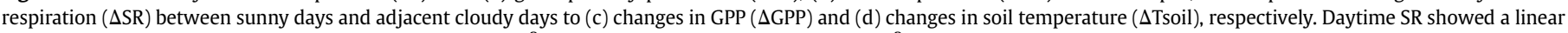

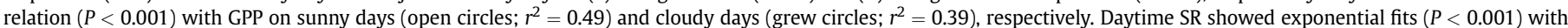

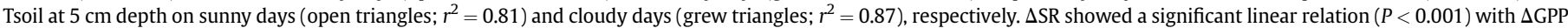
(black circles; $r^{2}=0.18$ ) and $\Delta$ Tsoil (black triangles; $r^{2}=0.43$ ), respectively.

et al., 2007). Thus, the isotopic approaches are probably not very useful for detecting the hourly time lags between photosynthesis and soil respiration on a diurnal scale. In contrast, through selecting 12 pair of sunny and cloudy days without disturbance to the plantsoil system, we found a signal that ecosystem photosynthesis regulates soil respiration on a diurnal scale with a short-term time lag.

However, in our study the effect of ecosystem photosynthesis on soil respiration was only observed in the 12 paired days and did not hold the whole growing season. Moreover, soil respiration could not be measured during the peak growing season (August and September) because surface water flooded the soil collars.

Table 2

Parameter descriptions of multiple linear regression analysis that significantly explained the changes in mean daytime soil respiration between sunny days and adjacent cloudy days during the growing season.

\begin{tabular}{llllll}
\hline \multirow{2}{*}{ Parameter } & $\Delta \mathrm{SR}^{\mathrm{a}}$ & & & & \\
\cline { 2 - 6 } & Coefficient & $S E$ & $F$ & \multicolumn{1}{c}{$P$} & Partial $r^{2}$ \\
\hline Constant & 0.07 & 0.05 & 1.38 & 0.150 & \\
$\Delta \mathrm{T}^{\mathrm{b}}$ & 0.10 & 0.01 & 7.65 & $<0.001$ & 0.43 \\
$\Delta \mathrm{GPP}^{\mathrm{c}}$ & 0.04 & 0.01 & 4.08 & $<0.001$ & 0.10 \\
Model $^{\mathrm{d}} r^{2}=0.53$ & & & & \\
\hline
\end{tabular}

${ }^{a} \Delta$ SR: Changes in daytime soil respiration $\left(\mu \mathrm{mol} \mathrm{CO} \mathrm{CO}^{-2} \mathrm{~s}^{-1}\right)$ between sunny days and cloudy days.

${ }^{\mathrm{b}} \Delta \mathrm{T}$ : Changes in daytime soil temperature at $5 \mathrm{~cm}$ depth $\left({ }^{\circ} \mathrm{C}\right)$ between sunny days and cloudy days.

c $\triangle$ GPP: Changes in gross primary production $\left(\mu \mathrm{mol} \mathrm{CO}_{2} \mathrm{~m}^{-2} \mathrm{~s}^{-1}\right)$ between sunny days and cloudy days.

${ }^{\mathrm{d}}$ Form of equation: $\Delta \mathrm{SR}=\mathrm{a}+\mathrm{b}^{*} \Delta \mathrm{T}+\mathrm{c}^{*} \Delta \mathrm{GPP}$.
Therefore, it is essential to have a more long-term, continuous datasets of soil respiration, GPP and other environmental factors for the entire growing period. Additionally, we did not separate soil respiration into autotrophic and heterotrophic sources. These limited data will increase the uncertainty about the effect of canopy

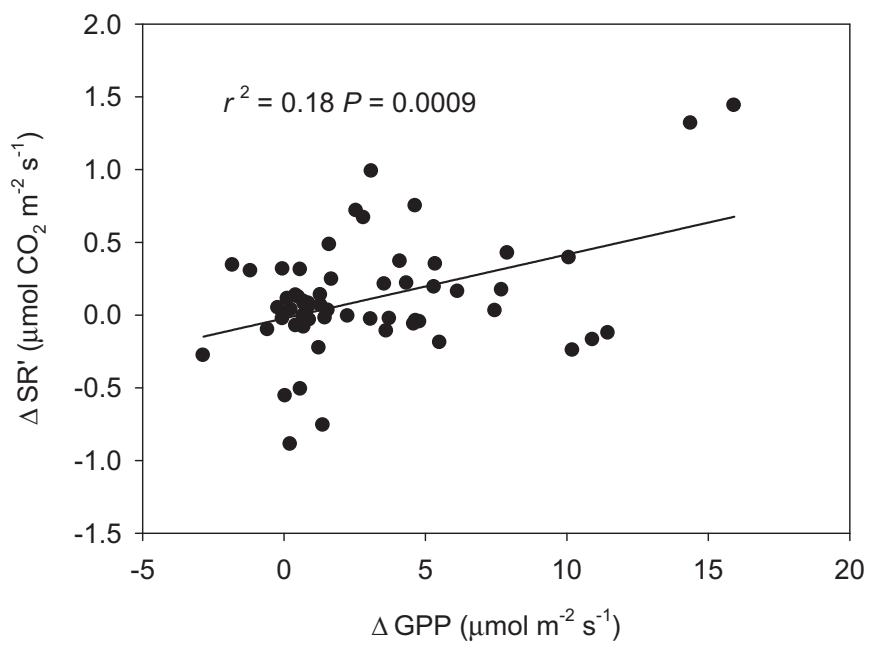

Fig. 6. $\Delta$ SR' showed a linear relation with $\Delta \mathrm{GPP}\left(r^{2}=0.18, P<0.001\right)$ during the growing season in a coastal wetland. $\Delta$ SR' represents the changes in daytime soil respiration between sunny and cloudy days under same soil temperature, and $\triangle \mathrm{GPP}$ represents the changes in gross primary production between sunny and cloudy days. 
photosynthesis on soil respiration. Hence, further research and some other approaches including isotope methods are needed to recognize the influence of photosynthesis on the different component of soil respiration (autotrophic and heterotrophic respiration), and the different roles of the biological and soil components of the ecosystem in determining the time lags (Stoy et al., 2007). Meanwhile, in order to incorporate photosynthetic inputs of carbon into the models of soil respiration, it is necessary to get more detailed information about the dynamics of the carbon flux from the vegetation canopy into belowground system and the coupling of photosynthetic assimilation and soil respiratory fluxes at different timescales.

\section{Conclusions}

Our results provided a clear signal that canopy photosynthesis regulates soil respiration on a diurnal scale with a time lag of about $0-4 \mathrm{~h}$. The short-term time lags indicate that the recent canopy carbon supply into soil might be respired quickly by soil respiration, so photosynthesis should be incorporated in soil carbon turnover models. Moreover, our results also provide further evidence that under the same soil temperature the changes in GPP regulate the changes in daytime soil respiration between sunny days and adjacent cloudy days. We therefore conclude that the effects of photosynthesis on soil respiration should be considered in order to accurately simulate the magnitude and temporal variation of soil respiration. Our results come from purely correlative analysis or statistical data by taking advantage of the natural shift of sunny and cloudy days, so it is necessary to get more detailed information and functional mechanism about the translocation of recent photosynthates to the rhizosphere and the speed of link between photosynthesis and soil respiration at different timescale.

\section{Acknowledgements}

This research was funded by the National Natural Science Foundation of China (No. 41301083), the National Science and Technology Support Program of China (No. 2011BAC02B01), and the Chinese Academy of Sciences (No. KZCX2-YW-223). We also thank Dr. Guangmei Wang, Peili Mao, Baohua Xie, and two anonymous reviewers for their expert advice and fruitful comments.

\section{References}

Armstrong, J., Armstrong, W., 1988. Phragmites australis - a preliminary study of soil-oxidizing sites and internal gas transport pathways. New Phytol. 108, 373382.

Armstrong, J., Armstrong, W., 1990. Light-enhanced convective throughflow increases oxygenation in rhizomes and rhizosphere of Phragmites australis (Cav.) Trin. ex Steud. New Phytol. 114, 121-128.

Bahn, M., Rodeghiero, M., Anderson-Dunn, M., Dore, S., Gimeno, C., Drösler, M. Williams, M., Ammann, C., Berninger, F., Flechard, C., Jones, S., Balzarolo, M., Kumar, S., Newesely, C., Priwitzer, T., Raschi, A., Siegwolf, R., Susiluoto, S. Tenhunen, J., Wohlfhart, G., Cernusca, A., 2008. Soil respiration in European grasslands in relation to climate and assimilate supply. Ecosystems 11, 13521367.

Bahn, M., Schmitt, M., Siegwolf, R., Richter, A., Brüggemann, N., 2009. Does photosynthesis affect grassland soil-respired $\mathrm{CO}_{2}$ and its carbon isotope composition on a diurnal timescale? New Phytol. 182, 451-460.

Baldocchi, D., Tang, J., Xu, L., 2006. How switches and lags in biophysical regulators affect spatial-temporal variation of soil respiration in an oak-grass savanna. J. Geophys. Res. 111, G02008.

Barthel, M., Hammerle, A., Sturm, P., Baur, T., Gentsch, L., Knohl, A., 2011. The diel imprint of leaf metabolism on the $\delta^{13} \mathrm{C}$ signal of soil respiration under control and drought conditions. New Phytol. 192, 925-938.

Bhupinderpal-Singh, Nordgren, A., Ottosson-Löfvenius, M., Högberg, M.N. Mellander, P.-E., Högberg, P., 2003. Tree root and soil heterotrophic respiration as revealed by girdling of boreal Scots pine forest: extending observations beyond the first year. Plant Cell Environ. 26, 1287-1296.
Blossfeld, S., Gansert, D., Thiele, B., Kuhn, A.J., Lösch, R., 2011. The dynamics of oxygen concentration, $\mathrm{pH}$ value and organic acids in the rhizosphere of Juncus spp. Soil Biol. Biochem. 43, 1186-1197.

Bond-Lamberty, B., Thomson, A., 2010. Temperature-associated increases in the global soil respiration record. Nature 464, 579-582.

Carbone, M.S., Czimczik, C.I., McDuffee, K.E., Trumbore, S.E., 2007. Allocation and residence time of photosynthetic products in a boreal forest using a low-level ${ }^{14} \mathrm{C}$ pulse-chase labeling technique. Glob. Change Biol. 13, 466-477.

Cardon, Z.G., Czaja, A.D., Funk, J.L., Vitt, P.L., 2002. Periodic carbon flushing to roots of Quercus rubra saplings affects soil respiration and rhizosphere microbial biomass. Oecologia 133, 215-223.

Cheng, W., Coleman, D.C., Carroll, C.R., Hoffman, C.A., 1993. In situ measurement of root respiration and soluble $\mathrm{C}$ concentrations in the rhizosphere. Soil Biol. Biochem. 25, 1189-1196.

Davidson, E.A., Holbrook, N.M., 2009. Is temporal variation of soil respiration linked to the phenology of photosynthesis? In: Noormets, A. (Ed.), Phenology of Ecosystem Processes. Springer, New York, pp. 187-199.

Davidson, E.A., Janssens, I.A., 2006. Temperature sensitivity of soil carbon decomposition and feedbacks to climate change. Nature 440, 165-173.

Ekblad, A., Boström, B., Holm, A., Comstedt, D., 2005. Forest soil respiration rate and $\delta^{13} \mathrm{C}$ is regulated by recent above ground weather conditions. Oecologia 143, 136-142.

Ekblad, A., Högberg, P., 2001. Natural abundance of ${ }^{13} \mathrm{C}$ in $\mathrm{CO}_{2}$ respired from forest soils reveals speed of link between photosynthesis and root respiration. Oecologia 127, 305-308.

Gaumont-Guay, D., Black, T.A., Barr, A.G., Jassal, R.S., Nesic, Z., 2008. Biophysical controls on rhizospheric and heterotrophic components of soil respiration in a boreal black spruce stand. Tree Physiol. 28, 161-171.

Gregory, P.J., Atwell, B.J., 1991. The fate of carbon in pulse labelled crops of barley and wheat. Plant Soil 136, 205-213.

Han, G.X., Yang, L.Q., Yu, J.B., Wang, G.M., Mao, P.L., Gao, Y.J., 2013. Environmental effects on net ecosystem $\mathrm{CO}_{2}$ exchange over a reed (Phragmites australis) wetland in the Yellow River Estuary, China. Estuar. Coasts 36, 401-413.

Han, G.X., Yu, J.B., Li, H.B., Yang, L.Q., Wang, G.M., Mao, P.L., Gao, Y.J., 2012. Winter soil respiration in different vegetation patches of Yellow River Delta, China. Environ. Manag. 50, 39-49.

Han, G.X., Zhou, G.S., Xu, Z.Z., Yang, Y., Liu, J.L., Shi, K.Q., 2007. Biotic and abiotic factors controlling the spatial and temporal variation of soil respiration in an agricultural ecosystem. Soil Biol. Biochem. 39, 418-425.

Högberg, P., Högberg, M.N., Gottlicher, S.G., Betson, N.R., Keel, S.G., Metcalfe, D.B., Campbell, C., Schindlbacher, A., Hurry, V., Lundmark, T., Linder, S., Näsholm, T. 2008. High temporal resolution tracing of photosynthate carbon from the tree canopy to forest soil microorganisms. New Phytol. 177, 220-228.

Högberg, P., Nordgren, A., Buchmann, N., Taylor, A.F.S., Ekblad, A., Högberg, M.N., Nyberg, G., Ottosson-Löfvenius, M., Read, D.J., 2001. Large scale forest girdling shows that current photosynthesis drives soil respiration. Nature 411, 789-792.

Högberg, P., Read, D.J., 2006. Towards a more plant physiological perspective on soil ecology. Trends Ecol. Evol. 21, 548-554.

Irvine, J., Law, B.E., Kurpius, M.R., 2005. Coupling of canopy gas exchange with root and rhizosphere respiration in a semi-arid forest. Biogeochemistry 73, 271282.

Kayler, Z., Gessler, A., Buchmann, N., 2010. What is the speed of link between aboveground and belowground processes? New Phytol. 187, 885-888.

Kuzyakov, Y., Cheng, W., 2001. Photosynthesis controls of rhizosphere respiration and organic matter decomposition. Soil Biol. Biochem. 33, 1915-1925.

Kuzyakov, Y., Cheng, W., 2004. Photosynthesis controls of $\mathrm{CO}_{2}$ efflux from maize rhizosphere. Plant Soil 263, 85-99.

Kuzyakov, Y., Ehrensberger, H., Stahr, K., 2001. Carbon partitioning and belowground translocation by Lolium perenne. Soil Biol. Biochem. 33, 61-74.

Kuzyakov, Y., Gavrichkova, O., 2010. Time lag between photosynthesis and carbon dioxide efflux from soil: a review of mechanisms and controls. Glob. Change Biol. 16, 3386-3406.

Kuzyakov, Y., Larionova, A.A., 2005. Root and rhizomicrobial respiration: a review of approaches to estimate respiration of autotrophic and heterotrophic organisms in soil. J. Soil Sci. Plant Nutr. 168, 503-520.

Liu, Q., Edwards, N.T., Post, W.M., Gu, L., Ledford, J., Lenhart, S., 2006. Temperatureindependent diel variation in soil respiration observed from a temperate deciduous forest. Glob. Change Biol. 12, 2136-2145.

Mencuccini, M., Hölttä, T., 2010. The significance of phloem transport for the speed with which canopy photosynthesis and belowground respiration are linked. New Phytol. 185, 189-203.

Moyano, F.E., Kutsch, W.L., Rebmann, C., 2008. Soil respiration fluxes in relation to photosynthetic activity in broad-leaf and needle-leaf forest stands. Agric. Forest Meteorol. 148, 135-143.

Nie, M., Zhang, X.D., Wang, J.Q. Jiang, L.F., Yang, J., Ouan, Z.X., Cui, X.H., Fang, C.M. Li, B., 2009. Rhizosphere effects on soil bacterial abundance and diversity in the Yellow River Deltaic ecosystem as influenced by petroleum contamination and soil salinization. Soil Biol. Biochem. 41, 2535-2542.

Phillips, C., Nickerson, N., Risk, D., Bond, B.J., 2011. Interpreting diel hysteresis between soil respiration and temperature. Glob. Change Biol. 17, 515-527.

Riveros-Iregui, D.A., Emanuel, R.E., Muth, D.J., McGlynn, B.L., Epstein, H.E., Welsch, D.L., Pacific, V.J., Wraith, J.M., 2007. Diurnal hysteresis between soil $\mathrm{CO}_{2}$ and soil temperature is controlled by soil water content. Geophys. Res. Lett. 34, L17404. 
Sampson, D.A., Janssens, I.A., Curiel Yuste, J., Ceulemans, R., 2007. Basal rates of soil respiration are correlated with photosynthesis in a mixed temperate forest. Glob. Change Biol. 13, 2008-2017.

Söderström, B., Read, D.J., 1987. Respiratory activity of intact and excised ectomycorrhizal systems growing in unsterilised soil. Soil Biol. Biochem. 19, 231-236.

Søe, A.R.B., Giesemann, A., Anderson, T.H., Weigel, H.J., Buchmann, N., 2004. Soil respiration under elevated $\mathrm{CO}_{2}$ and its partitioning into recently assimilated and older carbon sources. Plant Soil 262, 85-94.

Stoy, P.C., Palmroth, S., Oishi, A.C., Ward, E., Siqueira, M.B.S., Juang, J.Y., Novick, K.A. Johnsen, K., Katul, G.G., Oren, R., 2007. Are ecosystem carbon inputs and outputs coupled at short time scales? A case study from adjacent pine and hardwood forests using impulse-response analysis. Plant Cell Environ. 30, 700-710.

Tang, J., Baldocchi, D.D., Xu, L., 2005. Tree photosynthesis modulates soil respiration on a diurnal time scale. Glob. Change Biol. 11, 1298-1304.

Trinder, C.J., Artz, R.R.E., Johnson, D., 2008. Contribution of plant photosynthate to soil respiration and dissolved organic carbon in a naturally recolonising cutover peatland. Soil Biol. Biochem. 40, 1622-1628.

Vargas, R., Allen, M.F., 2008. Environmental controls and the influence of vegetation type, fine roots and rhizomorphs on diel and seasonal variation in soil respiration. New Phytol. 179, 460-471.
Vargas, R., Baldocchi, D.D., Bahn, M., Hanson, P.J., Hosman, K.P., Kulmala, L. Pumpanen, J., Yang, B., 2011a. On the multi-temporal correlation between photosynthesis and soil $\mathrm{CO}_{2}$ efflux: reconciling lags and observations. New Phytol. 191, 1006-1017.

Vargas, R., Carbone, M.S., Reichstein, M., Baldocchi, D.D., 2011b. Frontiers and challenges in soil respiration research: from measurements to model-data integration. Biogeochemistry 102,1-13.

Wan, S., Luo, Y., 2003. Substrate regulation of soil respiration in a tallgrass prairie: results of a clipping and shading experiment. Glob. Biogeochem. Cycles 17, 1054

Wingate, L., Ogée, J., Burlett, R., Bosc, A., Devaux, M., Grace, J., Loustau, D., Gessler, A. 2010. Photosynthetic carbon isotope discrimination and its relationship to the carbon isotope signals of stem, soil and ecosystem respiration. New Phytol. 188, $576-589$.

Xie, T., Liu, X.H., Sun, T., 2011. The effects of groundwater table and flood irrigation strategies on soil water and salt dynamics and reed water use in the Yellow River Delta, China. Ecol. Model. 222, 241-252.

Yan, L., Chen, S., Huang, J., Lin, G., 2011. Water regulated effects of photosynthetic substrate supply on soil respiration in a semiarid steppe. Glob. Change Biol. 17 1990-2001. 